\title{
Thyroid Artery
}

National Cancer Institute

\section{Source}

National Cancer Institute. Thyroid Artery. NCI Thesaurus. Code C53020.

A short arterial segment arising from the first segment of the subclavian artery that branches to form the inferior and superior thyroid arteries. 